\title{
Estrés oxidativo en la fibromialgia: fisiopatología e implicaciones clínicas
}

Mario D. Cordero

De forma general, se define al estrés oxidativo como el desequilibrio entre la producción de especies reactivas de oxígeno (ROS) y especies reactivas de nitrógeno (RNS), y los mecanismos de defensa antioxidante. Estas moléculas tóxicas se vuelven altamente reactivas en su formación debido a su alterado número de electrones de valencia desapareada. Corresponde a la mitocondria el ser la principal productora de ROS, generándose la mayor parte por los complejos de la cadena respiratoria I y III, consecuencia del flujo de electrones entre ambos complejos. Sin embargo, la producción de ROS en condiciones fisiológicas se vuelve esencial para la vida manteniéndose un nivel basal de ROS y están involucradas en numerosos mecanismos como la actividad bactericida de los fagocitos o la transducción de senales, la regulación del crecimiento celular o el estado rédox de la células, entre otros. Altos niveles de estrés oxidativo han sido involucrados como evento primario y/o secundario en numerosas patologías como artritis reumatoide, Parkinson, Alzheimer, arterosclerosis y patologías cardiovasculares, diabetes mellitus.

El estrés oxidativo en la fibromialgia

La fibromialgia (FM) es un síndrome de dolor crónico generalizado acompañado de otros síntomas como depresión, ansiedad, fatiga o alteraciones del sueño. Su diagnóstico se realiza a partir de los criterios de clasificación establecidos por el Colegio Americano de Reumatología de 1990 (ACR). En España presenta una alta prevalencia: el 2,4\% de la población mayor de 20 años y con una mayor presencia en mujeres que en hombres, en una relación de 21:13. A pesar de la alta prevalencia, su etiología resulta aún desconocida y no existen tratamientos efectivos. En los últimos anos, el estrés oxidativo ha adquirido un relevante papel en la fisiopatología de la FM. Peroxidación lipídica $(\mathrm{PL})$ y proteínas carboniladas, productos finales del dano en la membrana inducidos por las ROS, se han observado incrementados en el plasma de pacientes con FM. Por otro lado, la capacidad total antioxidante o enzimas antioxidantes como la superóxido dismutasa (SOD) o la catalasa se han podido observar disminuidas en el plasma de los pacientes con FM. Todas las investigaciones han sido orientadas al plasma o el suero de pacientes como modelo de estudio, surgiendo la necesidad del uso de modelos celulares, es decir, el lugar donde se activa y controla la maquinaria de producción de ROS. A este respecto, el peróxido de hidrógeno (H2O2), como uno de los radiales libres que proviene del oxígeno formando parte de las ROS, se ha encontrado incrementado en neutrófilos de pacientes con FM. Del mismo modo, altos niveles del anión superóxido de origen mitocondrial (O2 -) se han observado en células mononucleares de sangre periférica de pacientes con FM. En este mismo modelo, los pacientes presentaron bajos niveles de CoQ10, un elemento de vital importancia en la cadena respiratoria mitocondrial cuya misión principal es el transporte de electrones de los complejos I y II al III, además de regular el acoplamiento de proteínas, el poro de transición mitocondrial y la beta-oxidación de ácidos grasos, así como un importante antioxidante de membrana, por lo que una deficiencia del mismo induce en la célula una bajada de la actividad de los complejos II + III, complejo III y complejo IV; además reduce la expresión de proteínas mitocondriales involucradas en la fosforilación oxidativa, disminuye el potencial de membrana mitocondrial e incrementa la producción de ROS. Pero, desde un punto de vista fisiopatológico, ¿qué relación puede existir entre el estrés oxidativo y los síntomas de la FM? Es sabido que la PL refleja la producción intracelular de las ROS, y se sabe que las ROS están involucradas en la etiología de uno de los síntomas más importantes de la FM: el dolor. El radical superóxido juega un importante papel respecto del desarrollo del dolor; por un lado, mediante sensibilización periférica y central del sistema nervioso y por tanto induciendo una alteración de la nocicepción, y por otro lado, mediante la activación de varias citoquinas como TNF-alfa, IL-1beta e IL-6(8). 
El papel de las citoquinas en la FM ha sido ampliamente discutido, si bien, no como mecanismo etiológico, pero sí como un factor relevante en el agravamiento de la sintomatología. Aunque los mecanismos por los cuales el estrés oxidativo puede alterar la sensibilidad muscular aún resultan desconocidos, es posible que el daño oxidativo interfiera en los músculos mediante una disminución de los nociceptores a nivel local, lo que provoca una disminución del umbral del dolor. Por otro lado, la PL ha sido relacionada con un 16 síntoma típico de la FM: la fatiga. Altos niveles de PL, así como una interesante correlación con este síntoma, se han demostrado en el síndrome de fatiga crónica, una patología con un alto porcentaje de comorbilidad con la FM. Otro de los síntomas propios de la FM: la depresión, ha mostrado una alta correlación entre la PL en eritrocitos de pacientes diagnosticados de depresión mayor y los valores obtenidos en la escala Hamilton de depresión, resultado en concordancia con los obtenidos en FM. Es interesante que se hayan observado correlaciones significativas entre los niveles de antioxidantes tanto en plasma como en suero con respecto a la puntuación obtenida en una escala analógica visual de dolor, así como al grado de rigidez matutina presentada por los pacientes. Por otro lado, la PL en suero sí ha demostrado un alto grado de correlación con el nivel de depresión presentado por los pacientes con FM, lo que demuestra la relación existente entre el balance oxidante/antioxidante y la sintomatología de la FM.

Implicaciones clínicas del estrés oxidativo en la fibromialgia

Desde un punto de vista clínico, nos interesa centrarnos en un aspecto de la FM que aún presenta grandes incógnitas y que constituye uno de los principales problemas de esta enfermedad: la carencia de tratamientos efectivos. Esto lleva a los especialistas al tratamiento sintomático de la enfermedad, llevando en ocasiones a un agravamiento del trastorno por los efectos secundarios que acarrean, y es que en muchos casos, estos fármacos inducen un aumento del estrés oxidativo. La CoQ10 ha demostrado en ensayos in vitro con células mononucleares de sangre periférica de pacientes con FM, ya sea por su papel antioxidante o por compensación del déficit, reducir significativamente los niveles de ROS, así como la degradación mitocondrial por vía autofágica más conocida como mitofagia. Este resultado, aunque in vitro, podría aportar información sobre el efecto beneficioso obtenido en pacientes tras la administración de CoQ10 junto con Gingko biloba mostrado por un estudio piloto en el que se observó una importante mejora en la calidad de vida de los pacientes. La fatiga, uno de los síntomas más típicos de la FM, se ha visto reducida por el tratamiento con CoQ10, tanto en modelos animales como en fatiga física en humanos tras el ejercicio. Asimismo, cabe destacar que la CoQ10 ha demostrado reducir el dolor muscular en pacientes inducido por el uso de estatinas, $y$ en modelos animales ha demostrado tener cualidades antiinflamatorias $y$ antinociceptivas, y es que recientemente se ha observado como la CoQ10 regula la expresión de ciertos genes de citoquinas pro-inflamatorios como el TNF-alfa, cuyo papel ya ha sido descrito en la FM. Por otro lado, la melatonina, una importante molécula sintetizada de forma endógena por el organismo y con propiedades antioxidantes, ha demostrado reducir los niveles de dolor en FM, así como síntomas más complejos y típicos de esta enfermedad como la depresión, la ansiedad o trastornos del sueño. Las terapias mediante antioxidantes han demostrado ser eficientes en numerosos procesos patológicos en los que el estrés oxidativo juega un papel relevante tanto de forma primaria como secundaria. La CoQ10, la Vitamina E o alpha-tocopherol, la vitamina $C$ o ácido ascórbico, la melatonina, la SOD, la vitamina A o retinol, el glutatión, la $\mathrm{N}$-acetilcisteína, etc., son algunos de los antioxidantes más usados en ensayos aleatorizados en pacientes de muy diversas patologías o como cotratamiento con fármacos que inducen grandes efectos secundarios como los tratamientos quimioterápicos. La CoQ10 se ha aplicado con éxito en ensayos clínicos en procesos patológicos como Parkinson, Alzheimer, ataxia de Friedreich, migraña, trastorno humano por deficiencias de CoQ10, cardiomiopatías o mitopatías inducidas por uso de estatinas. La falta de resultados que muestren aspectos negativos como efectos secundarios o algún grado de interferencia con otros tratamientos avala de algún modo el uso de terapias antioxidantes. 
Sin embargo, en el caso de la FM aún no existen ensayos controlados, a doble ciego y con placebo en los que se demuestren los posibles mecanismos beneficiosos de este tipo de terapias en general, y de la CoQ10 en particular. La enorme complejidad de esta enfermedad hace difícil la evaluación de su eficacia como tratamiento único, por lo que requiere un enfoque terapéutico multidisciplinar en el que el uso de antioxidantes adquiriría un papel como cotratamiento. Aunque el estrés oxidativo en la FM es un hecho aceptado, su papel en la enfermedad desde un punto de vista fisiopatológico aún no está claro, desconociéndose el mecanismo por el cual altos niveles de radicales libres, bajos niveles de antioxidantes o ambos procesos a la vez pueden llegar a influir en el agravamiento de los síntomas. Por tanto, son necesarios nuevos estudios en este sentido, así como el diseño de ensayos controlados sobre el efecto terapéutico de los antioxidantes. 